\title{
Perceptions of Deaf Characters in Adolescent Literature
}

C arla, one of my former students, sent me an email requesting summer reading recommendations. Her only stipulation was that she wanted to read about characters similar to herself. As teachers, we often try to hook our students on reading by presenting books with characters with whom they can relate. Such books can help increase their overall knowledge of the world, open their minds to multiple realities and variations of the human experience and provide scenarios in which they can live vicariously.

Carla's request is more complicated than one might presume. She is a deaf student who attends a residential school for the deaf and views herself as a member of a linguistic cultural minority, not a member of a disabled group. Historically, authors have used deafness as a literary device to relay various messages about the struggles of humankind and elicit sympathy from readers (Batson \& Bergman, 1985; Bergman, 1987; Burns, 1950; Krentz, 2002; Panara, 1972; Taylor, 1974, 1976a, 1976b, Schwartz, 1980; Wilding-Diaz, 1993). I knew that Carla did not want to read novels that pitied her or her peers. She wanted to read about characters who use American Sign Language and participate as members within the "Deaf"1 community. She does not want to read didactic books

1 I refer to "Deaf' as representing individuals who identify in a linguistic, cultural minority group. The term 'deaf' is used as a more generic term given to individuals with some degree of hearing loss. In other articles, 'deaf' has been used pejoratively or in connection to a view by those who believe one without the sense of hearing is inferior or lacking. I do not believe or wish to imply that. about deafness, but instead wants books with unpredictable plots and believable characters.

As an educator, I have sought and read numerous books about deafness. While memoirs and biographical selections have been relatively easy to acquire, finding fictional books for adolescents including deaf characters has been more challenging.

In recent decades, however, the general public's awareness of and perhaps interest in deaf people has risen along with that of our increasingly multicultural world. Educational legislation has increased awareness of the deaf as has news coverage of Gallaudet University protests. In addition, Deaf people have benefited from advances in communicative technology, such as Video Relay (VRS) and instant messaging pagers, more coordinated interpreting services and an increase in awareness of American Sign Language. Authors are incorporating more deaf characters than they did in the past. However, this increase does not necessarily translate to an increase in understanding of the deaf, nor does it translate to the most accurate, respectably, well-rounded characterization of the deaf. This dilemma, along with Carla's request, provided me with an interesting topic for study.

\section{Problem and Purpose}

Acquiring fictional books that include deaf characters can be time-consuming and challenging for teachers and librarians. The research examining deaf characters in fiction is extremely limited (Burns, 1950; Guella, 1983; Krentz, 2002; Wilding-Diaz, 1993). The most recent articles predominately focus on children's 
literature-specifically picture books (Bailes, 2002; Brittain, 2004). Despite decades of research affirming culturally authentic children's literature and the merits of multicultural literature, a coexisting body of research reveals the lack of culturally authentic texts

(Applebee, 1992; Campbell \& Wirtenberg, 1980;

As an educator, I want all of my students to have unlimited opportunities for the future without facing the disadvantages wrought by stereotyping. Ernest, 1995; Larrick, 1965; Sherriff, 2005; Taxel, 1986). Moreover, children's books with deaf characters are used as informational depictions of deaf individuals (Bockmiller, 1980). Readers of such resource books, typically parents, teachers and their students, gain information about deafness and individuals with "disabilities" (Bockmiller, 1980; Civiletto \& Schirmer, 2000). If an important purpose for deaf characters in fiction is educational and informational, then I suggest that there is a need for the characters to be presented as realistic models of deaf people. If not, the readers of such fiction gain inaccurate information about deafness including reinforced negative stereotypes, as can occur in any other literature portraying cultural minorities.

Similar to authors' informational depictions, writers also reveal societal understanding of groups of people through their fiction (Banfield \& Wilson, 1985; Panara, 1972; Rudman, 1984). Literature has often stigmatized minority culture individuals based upon race, ethnicity, disability, gender and/or sexual orientation. While readers might recognize the negative depictions and dismiss them as harmless stereotypes, these portrayals could become a part of the unconscious of members of our society. If books continually reinforce stereotypical depictions of deaf people, individuals belonging to the group might be typecast and discouraged into a limited way of being. As an educator, I want all of my students to have unlimited opportunities for the future without facing the disadvantages wrought by stereotyping.

\section{The Study}

For the purposes of this study, I examined six contemporary adolescent literature books with deaf characters, including: Nick's Secret, by C. Blatchford; A Maiden's Grave, by J. Deaver; Of Sound Mind, by J. Ferris; Deaf Child Crossing, by M. Matlin; Apple is My Sign, by M. Riskind; and Finding Abby, by V. Scott. These were written by three deaf authors and by three hearing authors. My research was based upon the perceptions of adult readers who each read two of the before-mentioned books. I selected the participants from a criterion sampling and divided them into three groups: 1. Adults who had attended either a special program for the deaf or a residential school for the deaf, used American Sign Language, and identified themselves as deaf were considered for the deaf category of the study; 2 . Adults who were friends, family members, co-workers or professionals in fields connected with individuals who identify themselves as deaf were considered for the familiar category of the study; and, 3. hearing adults who were not aware of the everyday experiences of deaf people and who had not taken a sign language class or worked with or lived with a deaf person were considered for the unfamiliar category of the study. Nine participants were selected for each group, totaling 27 participants.

To elicit the perspectives of my participants, I developed a Reader Response survey which was modeled after Schwartz's (1980) “Criteria for Analyzing Books about Deafness.”

\section{The Participant-Readers' Perceptions}

Participants commented on fourteen main and secondary characters. Their perceptions of these characters fall into six categories: the "normal" curious kid such as the characters Harry (Apple is My Sign), Jeremy (Of Sound Mind) and Jared (Finding Abby); the egocentric spoiled brat such as Palma (Of Sound Mind) and Megan (Deaf Child Crossing); the advocate such as Harry's mother (Apple is My Sign) and Susan (A Maiden's Grave); those dependent upon the majority culture such as Palma (Of Sound Mind) and Lizzie (Deaf Child Crossing); those isolated such as Melissa (Finding Abby), Ben (Of Sound Mind), Nick (Nick's Secret) and Thomas (Of Sound Mind); and, those searching for their identities such as Melanie (A Maiden's Grave) and Abby (Finding Abby).

Overall, participants commented more frequently about the deaf characters in the books by the hearing authors (A Maiden's Grave; Of Sound Mind; Apple is 
My Sign) and made more positive comments about the culturally Deaf male characters, particularly Ben Roper, Jeremy and Thomas of Of Sound Mind, and Harry of Apple is My Sign.

\section{The Characters}

\section{Ben Roper (Of Sound Mind)}

Regardless of Dr. Roper's minor-character status, he was liked by all three participant-groups; however, they noted that he was often isolated from other deaf people which seemed unusual for a culturally Deaf person whose first language is American Sign Language. Readers cannot be certain whether his isolation is due to his recent move, by choice, or because of his type of employment.

One deaf participant explained, "He’s a computer engineer working on a project at Penn State . . . Ivy (his daughter) mentions in passing how her father communicates-using technology like a lot of deaf folks do . . . . Dr. Roper seems to have a peaceful, satisfactory relationship with his daughter, Ivy. He welcomes Jeremy and Thomas into his workshop and involves them in his model-making . . . . Dr. Roper might epitomize that deaf people can be successful in their field" (6d).

Another deaf participant described him as, "[t]he educated, professional college graduate who doesn't socialize much with other deaf. I have met and known a lot of deaf people that fit the descriptions like Dr. Roper, highly educated, capable deaf professionals in good jobs, and somewhat isolated"(9d).

As a successful, educated professional, Dr. Roper serves as an exceptional model for young readers who can admire his intelligence, creativity, and his success as a single parent.

\section{Harry (Apple Is My Sign)}

Also known by his sign name, Apple, Harry attends a school for the deaf in Pennsylvania. This is a major change for him after growing up on a farm. Harry meets new deaf friends and learns from teachers through sign language. Harry is portrayed as a curious "normal” kid.

Overall, participants considered Harry to be a well-liked character. The familiar participants viewed Harry as a learner who becomes thrilled with new circumstances and situations. In one instance, Harry understands that using sign language publicly embarrasses his friend, Agnes, but remembers how his mother taught him to never be ashamed of being himself. When he forgets his hat on a train, he goes back to retrieve it. Instead of quickly and quietly leaving the train he stomps his foot to gain everyone's attention and signs "I'm going home for Christmas vacation. Merry Christmas.” He waves to the passengers. Many of the hearing people wave back to him (Riskind, 75-80). One familiar participant responded to that scene with Agnes. She wrote, "When she got off and joined her family, Apple noticed no one signed to her. I see that often where the parents never learn to communicate with their Deaf child"(4f).

The unfamiliar participants explained that although he is different from those in the majority culture, he is an "ordinary" child. An unfamiliar participant explained, "The book portrayed the children as ordinary children, which makes it easily identifiable to anyone who reads this book. It sends a message to children who can hear that deaf children truly aren't any different from themselves" $(7 \mathrm{u})$. Certainly for those who are unaware of deaf people and wish to gain further insight, this book encourages readers to approach diversity and difference as an engaging challenge, not something to fear.

\section{Jeremy (Of Sound Mind)}

Eleven-year-old Jeremy attends "special classes" for the deaf in a local public school as a fifth-grader. He is highly pressured to be successful being the only deaf son of two deaf parents. He works hard to do his best so that he is not a "freak or a failure" (Ferris, 4). Although a minor character who appears in few scenes and does not say much, Jeremy received a significant amount of attention from the participants. Overall, he was well-liked by them. One participant 
wrote, "I think Jeremy is the best role model for deaf children/teens. He is a typical deaf child, struggling in school, needing help with homework from his hearing brother and seems to be reasonably well-adjusted in most areas . . . the normal deaf child of deaf parents"(9d).

Similar to the character, Harry, Jeremy is selfconfident. He volunteers to help deliver food to his elderly neighbors, enjoys hanging out with his school peers, and participates in sports.

\section{Thomas (Of Sound Mind)}

Thomas, father and carpenter, is one of the main characters in Of Sound Mind. His character was adored by the participants but some wonder why he did not try to communicate better with the hearing

\section{Participants commented} more frequently about the culturally Deaf male characters. Although the participants were divided in their responses to the various female characters, all of the female characters were criticized except for one minor character,

\section{Susan.}

feels about different aspects of being deaf" and noted that "Thomas and Jeremy are accepting of their deafness and do, or at least try, not to limit themselves" (6u).

Once more, participants commented more frequently about the culturally Deaf male characters. Although the participants were divided in their responses to the various female characters, all of the female characters were criticized except for one minor character, Susan.

\section{Susan (A Maiden's Grave)}

Seventeen-year-old Susan is a high school honors student who had received early acceptance to Gallaudet University on a full scholarship for the following semester. Susan's parents were deaf which the other characters consider the "highest in the hierarchy of the world of the Deaf" prelingually deaf, born to deaf parents (Deaver, 86). Susan is "unyielding about the use of ASL . . . . militantly rejecting oralism- the practice of forcing the deaf to try to speak" (Deaver, 87).

Susan is frequently yet briefly mentioned in the participants' comments mostly because she is a minor character who appears only in the beginning of the book and is shot and killed as an example of the kidnappers' intolerance of difference. Nevertheless, readers enjoyed her resilience and leadership abilities in the face of danger. One deaf participant pondered over the character in connection to her own identity and wished she was able to ask the character specific questions.

While Susan is a character I believe my former student would appreciate reading about in a novel, the other female deaf characters did not receive such high praise from participants. The major criticism was that these female characters remained weak and, at times, pathetic.

\section{Melanie (A Maiden's Grave)}

Melanie is an eighteen-year-old junior teacher at the Laurent Clerc School, where she had previously attended as a student. Melanie lost her hearing postlingually at eight years old and "was a better lip reader than most"(Deaver, 9).

Many of the participants viewed Melanie as someone who relies solely on her "other" senses to 
cope and as one who longs to regain her hearing. One familiar participant explained, "[Her] personality seemed to be totally built on the strength of her 'other senses' since she was Deaf"(8f). These other senses include Melanie's ability to "smell the river" (Deaver, 176) and her phenomenal clairvoyance.

\section{Lizzie (Deaf Child Crossing)}

Lizzie is a minor character who uses only sign language and doesn't speak; she attends the Illinois School for the Deaf; and, she does not use hearing aids because her parents say she does not need them (Matlin, 126). When readers first meet Lizzie, she has just arrived at camp believing that she is the only deaf camper. She is quickly befriended by another deaf camper and the two communicate through sign language. Lizzie leads camp cheers and teaches informal sign language classes.

The participants mentioned Lizzie only because her behavior was so unrealistic and unlikely to occur. Throughout the story, she is independent and sociable; yet, one significant discrepancy is after the main character, Megan, runs away and is rescued. Lizzie tells Megan “we” shouldn’t go off alone since "we" are deaf. This infuriates Megan, who longs for the independence other girls at the camp have (Matlin, 177). My participants sarcastically pondered whether all children shouldn't run away or just deaf children. Regardless, Lizzie's response differed from her previous 'deaf people can do anything but hear'2 behaviors.

\section{Palma (Of Sound Mind)}

Palma, the mother and artist, is one of the main characters in Of Sound Mind. Palma is a Deaf person from a Deaf family who attended Gallaudet University. Although she is highly successful with her art, Palma is not easy to like. The deaf participants focused on her personality and explained why they believed she was or was not realistic as a character. One participant explained, "Palma-talented but dependent, not trusting the 'hearing world' but has to be part of it in order to profit from her work. She is self-conscious about her English and her hearing son sees her as selfish and demanding" (6d).

2 Former Gallaudent University President I. King Jordan's statement.
Another deaf participant selected Palma "as being the most unlike a deaf person." The participant felt that because of her Deaf family Palma should have been more independent. The participant wrote, "She is too overly dependent on her hearing son, too helpless, too afraid, too high strung and too much the Prima Donna to be 'real' "(9d).

One familiar participant wrote, "The mother was withdrawn from the hearing world. She was afraid to try to communicate with hearing people. The mother called her hearing son 'just you' not necessarily approving of his hearing"(3f).

Both Lizzie and Palma could be seen as positive role models for their numerous successes; yet, their behavior appears as outliers and makes them unrealistic and unbelievable.

\section{Conclusions}

Participants across all three groups mentioned their preference for a spectrum of deaf characters. The books used in this study that were written by hearing authors included a variety of characters. For example, Riskind's Apple Is My Sign includes numerous deaf students at a school for the deaf and the main character living within a deaf family; Deaver's A Maiden's Grave includes more deaf characters from a variety of backgrounds and a few hearing characters; and Ferris' Of Sound Mind includes two deaf families again with more deaf characters than hearing characters.

The books written by the deaf authors in this study include only a few deaf characters. For example, Matlin's Deaf Child Crossing includes two deaf girls; Scott's Finding Abby includes more minor deaf characters but readers learn about these characters from the hearing characters' perspectives. For instance, the character Jared uses sign language and 
attends a residential school for the deaf, but readers learn this information from his hearing mother talking about him, not from the character's words. Readers know that he communicates because we are told that he does; however, the only communication readers are shown is a wave from the child. With the fewer deaf characters, it is nearly impossible for the various ways of being deaf to be included in the book. Thus, the preference for the books by the hearing authors may be connected to the preference for a variety of deaf people represented.

Themes such as the

\section{Examples to demonstrate}

the isolation some of the deaf characters experience include Nick of Nick's Secret being the only deaf character in his story and Ben Roper of $O$ f

\section{Sound Mind being the} only deaf employee in his workplace. While these can certainly be read as negative situations the characters experience, isolation may be a reality that resonates in some deaf people's experiences. characters being dependent and isolated from others did arise. For example, Palma in Of Sound Mind insists that her hearing son act as her personal interpreter so that she can avoid other hearing people. Examples to demonstrate the isolation some of the deaf characters experience include Nick of Nick's Secret being the only deaf character in his story and Ben Roper of Of Sound Mind being the only deaf employee in his workplace. While these can certainly be read as negative situations the characters experience, isolation may be a reality that resonates in some deaf people's experiences. With communicative technology and more individuals fluent in American Sign Language, some deaf individuals may decide to associate more with individuals in the larger culture. One must interpret purposeful isolation such as Ben Roper's (Of Sound Mind) case, working in a location that provides him with the best employment opportunities, differently than Melissa Black's Finding Abby isolating feelings of being left out of family dinner discussions.
Similarly, variations in characterization including the egocentric, spoiled brat and those searching for their identities are common themes in adolescent literature with or without deaf characters being included. Positive examples of deaf characters including the roles of the advocate such as Susan (A Maiden's Grave) and Harry's mother (Apple is My Sign), along with descriptions of regular everyday deaf kids increases the varieties of deaf characters.

Consider again my student Carla and her longing to read about deaf characters. I hope my research assists teachers in recommending books with characters to which our students can relate and in recommending books with multiple realities of the deaf human experience. When presented accurately, readers learn about a reality often quite different from their own experiences. The portrayal of realistic deaf characters benefits adolescent readers. Deaf characters in fiction act as role models for young adults. A positive portrayal of deaf characters benefits deaf adolescents whether or not they see themselves as biologically deaf or culturally deaf. Just like my student Carla, deaf adolescents wish to find themselves and their peers in the novel.

Sharon Pajka-West holds a Ph.D. in English Education from the University of Virginia and a master's degree in Deaf Education from Gallaudet University. She is currently an instructor in the Department of Applied Literacy at Gallaudet University.

\section{Works Cited}

Bailes, Cynthia.Nees. "Mandy: A Critical Look at the Portrayal of a Deaf Character in Children's Literature." Multicultural Perspectives, 4.4 (2002): 3-9.

Batson, Trenton. "The Deaf Person in Fiction: From Sainthood to Rorschach Blot:" Interracial Books for Children Bulletin, 11.1, 11.2 (1980): 16-18.

Batson, Trenton. \& Bergman, Eugene. Angels and Outcasts: An Anthology of Deaf Characters in Literature. Washington, D.C.: Gallaudet University Press, 1985.

Bergman, Eugene. "Literature, Fictional Characters." In J.V. Van Cleve (Ed.) Gallaudet Encyclopedia of Deaf People \& Deafness. Gallaudet College, Washington, D.C.: McGraw Hill Book Company, 1987.

Brittain, Isabel. "An Examination into the Portrayal of Deaf Characters and Deaf Issues in Picture Books for Children." Disability Studies Quarterly, Winter 24 2004. 1. Retrieved April 24, 2005 from http://www.dsq-sds.org

Burns, D.J. An Annotated Checklist of Fictional Works which Contain Deaf Characters. Unpublished master's thesis, Gallaudet University, Washington, D.C, 1950. 
Campbell, P. \& Wirtenberg, J. "How Books Influence Children: What the Research Shows." Interracial Books for Children Bulletin, 11.6 (1980): 3-6.

Civiletto, Christine L. \& Schirmer, Barbara R. "Literature with Characters Who are Deaf. The Dragon Lode, 9.1 (Fall 2000): 46-49.

Guella, Bernard. "Short Stories with Deaf Fictional Characters." American Annals of the Deaf, 128.1 (1983): 25-33.

Krentz, Christopher. "Exploring the 'Hearing Line:' Deafness, Laughter, and Mark Twain. In S. L. Snyder, B. J. Brueggemann \& R. Garland-Thomson, ed. Disability Studies: Enabling the Humanities. New York, The Modern Language Association of America, 2002. 234-247.

Larrick, Nancy. "The All-White World of Children's Books." Saturday Review, 11 (1965): 63-85.

Panara, Robert. "Deaf Characters in Fiction and Drama." The Deaf American, 24.5 (1972): 3-8.

Schwartz, A.V. (1980). "Books Mirror Society: A Study of Children's Materials." Interracial Books for Children Bulletin, 11.1 \& 11.2 (1980): 19-24.

Sherriff, Amanda J. The Portrayal of Mexican American Females in Realistic Picture Books (1998-2004). University of North Carolina, Chapel Hill, 2005.

Taxel, Joel. (1986). "The Black Experience in Children's Fiction: Controversies Surrounding Award Winning Books." Curriculum Inquiry, 16 (1986): 245-281.

Taylor, G.M. "Deaf Characters in Short Stories: A Selective Bibliography." The Deaf American. 26.9 (1974): 6-8.
Taylor, G.M. "Deaf Characters in Short Stories: A Selective Bibliography II." The Deaf American. 26.9 (1976a): 13-16.

Taylor, G.M. "Deaf Characters in Short Stories: A Selective Bibliography III." The Deaf American. 26.9 (1976b): 27-28.

Wilding-Diaz, Minnie Mae. Deaf Characters in Children's Books: How are They Portrayed? Unpublished master's thesis, Brigham Young University, Provo, UT, 1993.

Wilding-Diaz, Minnie Mae. "Deaf Characters in Children's Books: How are They Perceived?" In Gallaudet University College for Continuing Education, Snider, B.D. (Ed.) Journal: Post Milan ASL \& English Literacy: Issues, Trends \& Research, Conference proceedings October 20-22, 1993.

Adolescent Fiction Books Reviewed

Blatchford, Claire. Nick's Secret. Minneapolis, MN: Lerner Publications Company, 2000.

Deaver, Jeffrey. A Maiden's Grave. New York: A Signet Book, 1995.

Ferris, Jean. Of Sound Mind. New York: A Sunburst Book, 2001.

Matlin, Marlee. Deaf Child Crossing. New York: Aladdin Paperbacks, 2002.

Riskind, Mary. Apple is My Sign. Boston, MA: Houghton Mifflin Company, 1981.

Scott, Virginia M. (2000). Finding Abby. Hillsboro, OR: Butte Publications, Inc., 2000. 